Article

\title{
University-State Child Welfare Training Partnerships: The Challenge of Matching Dollar Contributions
}

\author{
Jerry D. Marx * and Melissa Wells
}

Department of Social Work, University of New Hampshire, Durham, NH 03824, USA; E-Mail: Melissa.Wells@unh.edu

* Author to whom correspondence should be addressed; E-Mail: Jerry.Marx@unh.edu; Tel.: +1-207-752-0347; Fax: +1-603-862-4374.

Received: 2 September 2013; in revised form: 10 October 2013 / Accepted: 28 October 2013 / Published: 6 November 2013

\begin{abstract}
Universities are uniquely positioned to provide the very best training opportunities to public child welfare workers. However, university-child welfare agency training partnerships require a significant commitment of time and resources by university personnel at a time of extensive state cuts to public higher education. This national survey of university partnership administrators found significant differences among university respondents involving length of the contractual relationship, matching dollar requirements, and overall satisfaction with the training partnership.
\end{abstract}

Keywords: child welfare training; social administration; university partnerships; university engagement; contract administration

\section{Introduction}

Training partnerships between universities and state child welfare agencies require a significant commitment of time and resources by university personnel at a time of extensive state cuts to public higher education in the United States [1]. In addition to the challenges of administering a partnership between two diverse bureaucracies, U.S. universities can find the matching dollar (or "cost share") requirements that are a part of many contracts to be particularly challenging to meet. Yet sustaining commitments from universities to promote excellence in the training of public child welfare workers remains a pressing need in the United States. Consider the following: the Children's Defense Fund 
claims that, in the United States, a child is abused or neglected every 42 seconds [2]. The U.S. Department of Health and Human Services (DHHS) reports that in Federal Fiscal Year 2011, which runs from 1 October 2010 to 30 September 2011, over two million reports of child maltreatment received a Child Protective Services (CPS) response and disposition. In about eight out of ten (81.2\%) cases of substantiated child victimization, the perpetrator was a parent either acting alone or with some other person. About a quarter of these child victims (27.1\%) were under three years of age [3]. Consequently, the prevention of child maltreatment, which includes abuse and neglect, continues to be a major concern of state child welfare agencies. Projected population increases make the challenge that much greater. More specifically, there were 73.9 million children in the United States in 2011, which represents a 1.5 million increase since 2000. By 2050, this number is expected to increase to 101.6 million [4]. In the context of these projections, sustaining effective training partnerships between public child welfare agencies and university social work education programs should be a high public priority.

"Systems Theory", first introduced to professional social work with the publication of General Systems Theory by biologist Ludwig von Bertalanffy in 1968, was quickly adopted by the profession in the 1970s because it offers a framework to analyze a group of entities (e.g., objects or beings) that work in concert and produce some result. As such, it is particularly important in state child welfare systems because of the multiple systems (family, court, education, health, mental health, communities) with which state child welfare must collaborate to achieve positive child welfare outcomes. As in the case of university-state child welfare partnerships, healthy systems seek to form relationships with external systems that are based on reciprocity and mutual benefit. While social work education programs strive to provide students with opportunities for practical application of their academics, state child welfare agencies need access to current research and professional education for the purpose of internal staff training and development. In terms of an effective partnership, highly-trained child welfare professionals represent a positive external outcome for the university system and a positive internal outcome for the state child welfare system $[5,6]$.

The most noteworthy university-state child welfare training partnerships are funded under Title IV-E of the Adoption Assistance and Child Welfare Act of 1980, which aims to improve child welfare, social services, and aid to families with system-dependent children by supporting the social work education and training of child welfare workers. The funds can be used for basic core training for new employees as well as ongoing and specialized training. This 1980 act was later clarified and enhanced by the 1997 Adoption and Safe Families Act, which resulted in greater federal support of child welfare training partnerships to meet increased standards of care in child welfare. The characteristics of individual training partnerships vary in terms of the extent and nature of faculty participation, staffing, student participation, use of technology, community stakeholder involvement, additional funding sources, and range of services. For example, the University of Vermont operates a child welfare training partnership with the State of Vermont's Department of Children and Families. It is noted for its wide range of services offered, including educational preparation at the undergraduate and graduate social work levels, in-service staff training, institutes and workshops, technical assistance with program design and evaluation, curriculum development, student placement, and grant writing assistance. Another highly respected partnership is the Pennsylvania Child Welfare Training Program at the University of Pittsburgh. The Pennsylvania program has been recognized for its effective 
collaboration with multiple stakeholder systems, including state child welfare agencies and 67 county child welfare agencies. Furthermore, the program is now developing an online curriculum, which includes a three-course certificate in child advocacy. In Vermont, Pennsylvania, and other state training partnerships, the research skills of participating faculty members can be used to assess staff development needs, inform training curriculum, guide development of "program improvement plans", evaluate training programs, and facilitate overall organizational learning [7-9].

\section{Past Research}

The potential benefits of child welfare training partnerships are therefore considerable. However, university-state child welfare partnerships must be mutually beneficial for both systems if they are to receive continued university support and public funding. While some researchers have criticized the rigor and limited dissemination of past evaluations of the effectiveness of Title IV-E child welfare training programs, several studies have demonstrated the positive influence of social work education and training on the professional development of child welfare workers [7,10]. For instance, in a 1988 study by Lieberman, Hornby, and Russell that surveyed the educational backgrounds of child welfare workers, those with an MSW degree reported feeling the most prepared and most knowledgeable in the workplace, while BSW child welfare workers perceived their education as better preparation for their work than did those with bachelor degrees in areas other than social work [11]. Scannapieco \& Connell-Corrick surveyed current and past MSW Title IV-E students in 2003 and found that $70 \%$ reported increased ability to use interventions with clients and 74\% reported increased assessment skills [12]. Similarly, in a 1999 exploratory study of the impact of social work education on child welfare workers, researchers found that those who were either recent MSW graduates or current MSW students anticipating graduation within the year experienced increased confidence and sensitivity to clients as a result of their social work education [13]. As part of the same study, supervisors were also interviewed and confirmed the above behavior changes in their child welfare workers. In addition, supervisors reported an increase in types of interventions used by their caseworkers after involvement with social work education programs.

Professional social work training, in addition to promoting knowledge and skill development, is also positively associated with the retention of child welfare workers [14]. This is particularly important given that the field of child welfare - specifically public child welfare - is plagued with high turnover rates. A 2003 report from the General Account Office (GOA) indicated that the average length of employment for public child welfare workers was approximately two years [15]. High turnover in this field not only impacts the quality of service to children and families, it is also costly to agencies at a time of cuts in state spending. One study estimated the cost of training a new worker to be one-third to one-half the cost of a child welfare worker's annual salary [16]. Yet, research has found that turnover rates are lower among BSW and MSW child welfare workers, and that child welfare workers with social work degrees are most likely to indicate 'intent to stay' at their agency [17]).

Robin and Hollister in 2002 aimed to assess the impact of social work training on child welfare turnover using questionnaires and the available records of four cohorts of IV-E social work graduates [18]. Findings indicated that $93 \%$ of participants stayed in the field of child welfare after they had completed the IV-E obligation of employment, and 52\% continued in public child welfare settings 
after IV-E employment obligations, indicating that social work education may play a significant factor in the retention of child welfare workers. Additionally, almost all respondents were found to have provided significant contributions to the field of child welfare in such areas as policy leadership, program development, research, or teaching.

Partnerships between universities with schools of social work and child welfare agencies are also valuable, because knowledge transfer and more in-depth research can occur in these settings. With respect to research, the Institute for the Advancement of Social Work Research (IASWR) and Casey Family Programs conducted a study to explore existing and new strategies to build stronger research components to these training partnerships. As part of the study, the IASWR found that the most successful university-state child welfare training partnerships maintained close working relationships, set clear project timelines, "understood and learned from each other's cultures, planned for leadership transitions, and understood data sharing and confidentiality" [19].

Given the positive research findings on the value of social work education to the professional development of child welfare workers, further research needs to be done on the characteristics and successes of child welfare training partnerships and the unique challenges faced by the university faculty and staff members who administer these collaborations. Matching dollar contributions require that universities "share" in meeting the total costs of the training program. That is, a percent of the state's contract budget with the university must be matched with university resources. A dollar value is placed on all the employee time (faculty, administration) and other resources (student contributions, facility costs) that the university contributes to the contract. In a time of state cuts to education and increasing competition from for-profit online universities, these matching dollar requirements as well as other challenges in collaboration between these bureaucratic systems can threaten university commitment to child welfare training partnerships. Yet, there is little current empirical research on this topic $[20,21]$.

More specifically, this survey examined the following questions:

(1). What university resources, collaborations, and challenges are typically involved in training partnerships with state child welfare agencies?

(2). Are there significant differences between partnerships that require university matching dollar contributions and those that do not?

(3). Are there significant differences in partnership characteristics based on the length of the contractual relationship between university and state child welfare agency?

\section{Methods}

After gaining university I.R.B. approval, this study collected data using a web-based questionnaire given to participants nationwide over a three week period in the fall of 2011 . The online survey software program, SurveyMonkey, was utilized to administer the questionnaire. The participants for the study were university administrators from a list of 60 university-state child welfare agency training partnerships in the U.S. that were identified via partnership websites. A total of 26 partnership administrators replied to the survey invitation, but two respondents did not complete the survey and were not included in this analysis. Therefore, the sample size included here is 24 university-state partnerships. To test the validity of our survey instrument, a pretest of the questionnaire was done with 
university administrators and staff involved with the child welfare training partnership in the home state of the authors. Consequently, this program was not one of the 24 survey participants. Although no formal compensation was provided, a plan for sharing study results with participants to inform their individual practices was communicated prior to participation. The web-based survey included questions organized under the following subheadings: (1) administration/ organizing; (2) facilities; (3) faculty; (4) technology; (5) matching dollars; (6) collaboration; (7) challenges, and (8) and other partnership characteristics.

SPSS 19.0 was used for all quantitative analyses. Descriptive statistics were run for all survey frequencies. Cross-tabulations were run for comparisons among programs with and without a match requirement, as well as for an analysis of differences according to duration of the program.

\section{Findings}

These findings include descriptive statistics for all survey responses. To explore associations with matching dollar requirements, we used chi-square analyses to compare characteristics of respondents and institutions with and without a matching dollar expectation, as well as respondents' views of "collaboration" and "challenges" with "matching dollar expectation". Due to a small sample size, no multivariate analyses are included in this analysis.

\subsection{Descriptive Survey Responses}

\subsubsection{Characteristics of Partnerships and Respondents}

The majority of university respondents participating in this survey identified themselves as "project directors", while two were principal investigators on the training contract, one was a "training development specialist", and one was a "campus coordinator". In any case, all were involved with some aspect of administration in the training partnership. The primary service provided by university-state child welfare agency partnerships included child welfare training programs $(66.7 \%, \mathrm{n}=16)$, IV-E Tuition stipend/reimbursement for current students $(20.8 \%, \mathrm{n}=5)$, and other $(12.5 \%, \mathrm{n}=3)$. Pertaining to whom the primary service of the partnership was directed towards, responses included state employees $(41.7 \%, \mathrm{n}=10)$, students $(16.7 \%, \mathrm{n}=4)$, foster/adoptive families $(4.2 \%, \mathrm{n}=1)$, and "other" $(37.5 \%, \mathrm{n}=9)$. Of the "other" responses, five respondents answered that county employees were the primary service recipients and others listed MSW students and community partners.

Of the partnerships surveyed, $95.8 \%(n=23)$ said that curriculum development was an activity that supported the mission of their partnership while other responses included Core/Pre-service training $(83.3 \%, \mathrm{n}=20)$, Ongoing/In-service training $(83.3 \%, \mathrm{n}=20)$, conferences $75 \%(\mathrm{n}=18)$, field placements for students $(62.5 \%, \mathrm{n}=15)$, research $(62.5 \%, \mathrm{n}=15)$, summits $(37.5 \%, \mathrm{n}=9)$, and other activities $(8.3 \%, \mathrm{n}=2)$.

\subsubsection{Contracts between Child Welfare Partnership and University}

All university respondents $(n=24)$ stated that their partnership had a formal contract between the university and a state child welfare department. The length of this contract ranged from covering 12 months to 54 months. The majority of partnerships had a contract that covered 12 months $(62.5 \%$, 
$\mathrm{n}=15)$, while $12.5 \%(\mathrm{n}=3)$ of partnerships had contracts covering 24 months, $16.7 \%(\mathrm{n}=4)$ had contracts covering 36 months, $4.2 \%(n=1)$ had a contract covering 54 months, and $4.2 \%(n=1)$ had a contract that varied from 12 to 36 months.

The average length of the contractual relationship between university and state in our sample was 16.6 years $(\mathrm{SD}=7$ years). About $17 \%(\mathrm{n}=4)$ of partnerships stated their contact had been maintained for less than 10 years, $33 \%(\mathrm{n}=8)$ stated that their partnership had been maintained for 10 to 16 years, $25 \%(n=6)$ for 17 to 20 years, and $25 \%(n=6)$ of respondents had contracts maintained for over 20 years.

\subsubsection{Facilities}

The average number of locations for these partnerships was approximately four $(\mathrm{n}=4.46, \mathrm{SD}=5.0)$ with $50 \%(n=12)$ having one office location and other responses ranged from two to 18 . When asked where the partnership was headquartered, $91.7 \%(\mathrm{n}=22)$ of respondents stated it was at the university campus, $4.2 \%(\mathrm{n}=1)$ stated it was at a state-owned building, and one respondent stated that the partnership have five campus locations.

\subsubsection{Staffing}

About $71 \%(n=17)$ of respondents stated their partnership was staffed by university faculty and the same percent reported that the partnership had university staff. Other staffing responses included state employees $(20.8 \%, \mathrm{n}=5)$, independently hired staff $(33.3 \%, \mathrm{n}=8)$, and other staff $(8.3 \%, \mathrm{n}=2)$. Of the two "other" responses, one respondent said some partnership staff came from the university's research foundation. The other respondent said that although all their employees work for the university, many come from state child welfare positions and maintain that identity and culture.

When asked if faculty members contribute to the activities of the partnership, $87.5 \%(\mathrm{n}=21)$ said yes while $8.3 \%(n=2)$ said no. Respondents were presented with a list of activities and asked which, if any, do faculty members contribute to the partnership. Responses included training and presenting $(66.7 \%, \mathrm{n}=16)$, research $(58.3 \%, \mathrm{n}=14)$, consultation $(58.3 \%, \mathrm{n}=14)$, evaluation $(54.2 \%, \mathrm{n}=13)$, curriculum writing $(50 \%, \mathrm{n}=12)$, and panel discussions $(16.7 \%, \mathrm{n}=4)$. In addition to this, $16.7 \%(\mathrm{n}=4)$ stated faculty contribute in other ways.

\subsubsection{Technology}

Respondents reported on several forms of technology resources available to partnerships. These included online courses $(66.7 \%, \mathrm{n}=16)$, calendars $(54.2 \%, \mathrm{n}=13)$, news and announcements $(54.2 \%$, $\mathrm{n}=13)$, online external resources $(41.7 \%, \mathrm{n}=10)$, discussion boards $(29.2 \%, \mathrm{n}=7)$, virtual libraries $(25 \%, \mathrm{n}=6)$, blogs $(12.5 \%, \mathrm{n}=3)$, and other $(20.8 \%, \mathrm{n}=5)$. When asked if their partnership utilizes a password-protected learning management system (i.e., Blackboard), 58.3\% $(n=14)$ reported using such a system; 75\% $(\mathrm{n}=18)$ of respondents reported their partnership has its own website, and of those respondents who stated their partnership has its own website, $88.9 \%(\mathrm{n}=16)$ reported that the university maintains the website, $5.6 \%(\mathrm{n}=1)$ reported the state partner agency maintains the website, and $5.6 \%$ $(n=1)$ stated "other." The "other" response was specified to mean both agencies maintain the website. 


\subsubsection{Matching Dollars}

Seventy-one percent $(n=17)$ of university respondents stated that there is a percent of the partnership's state contract budget that must be matched with university resources while about $21 \%(n=5)$ stated the budget did not have to be matched. A dollar value is placed on the university matching contribution (faculty time, for example) in the contract. For partnerships who reported that there must be a percent of the budget that is matched, the percentage ranged from $10 \%$ to $100 \%$ with the median response being $25.5 \%$.

University respondents were also asked about specific ways that they generated matching dollars. Although $42 \%(\mathrm{n}=10)$ of partnerships stated they do not use students to generate matching dollars, others used undergraduate interns $(4.2 \%)$ and graduate interns $(20.8 \%)$ to generate "match". About $30 \%$ of respondents reported that their partnerships did not use faculty for generating match; however, others reported using faculty trainings $(8.3 \%)$, faculty research $(12.5 \%)$, faculty evaluation $(25 \%)$, faculty publications $(8.3 \%)$, and faculty as principal investigators $(25 \%)$ to generate match.

Other sources of university match included student academic coursework (12.5\%), curriculum development (25\%), discounted services (12.5), administration (29.2\%), tuition waivers (4.2\%), services from other university departments/programs (12.5\%), university facilities (33\%), and training conference income $(4.2 \%)$.

\subsection{Other Partnership Characteristics}

When asked if the partnership collaborates with any other university establishment besides the primary university partner, half $(50 \%, \mathrm{n}=12)$ stated they collaborate with organizations or associations while $37.5 \%(\mathrm{n}=9)$ stated additional academic departments, 33.3\% $(\mathrm{n}=8)$ stated professional centers, 33.3\% $(\mathrm{n}=8)$ stated institutes, 33.3\% $(\mathrm{n}=8)$ stated programs, and $8.3 \%(\mathrm{n}=2)$ stated "other". Respondents were asked if the partnership staff collaborate with any other colleges or universities in their state to carry out the primary functions of the partnership and about $67 \%(\mathrm{n}=16)$ said that was the case. Respondents reported that the universities involved with the partnerships ranged in size. About $46 \%$ had 20,000 or fewer students and 50\% had more than 20,000 students.

The majority of partnerships $(91.7 \%, \mathrm{n}=22)$ stated they receive IV-E funding as a public funding source for the partnership, 25\% $(\mathrm{n}=6)$ stated they receive IV-B funding, 25\% $(\mathrm{n}=6)$ stated they received CAPTA, and 37.5\% $(\mathrm{n}=9)$ stated "other". Other responses included state general funds $(\mathrm{n}=5)$, state and private grants, TANFF, JBAG, Mental Health Services Act funds, and foundation grants. Respondents were also asked about the approximate dollar amount of the state's share of the partnership's annual budget and responses ranged from zero to $\$ 40$ million with $\$ 700,000$ being the median response.

\subsubsection{Perceptions of Collaboration.}

Participants were asked on a scale from strongly agree (5) to strongly disagree (1) to reply to nine statements pertaining to perceptions of collaboration in their partnerships. Means are reported here and percentages for each answer category appear in Table 1. The highest average reported level of collaboration was 4.40 for "university able to meet contractual expectations" and the lowest mean 3.95 
for "university partner has organizational autonomy." Mean satisfaction with the partnership was 4.14, mean satisfaction with the level of involvement from the state was 4.09 , while the mean rating of "states' ability to meet contractual expectation" was 4.31. Average ratings of whether there was "good state and university communication" were 4.18 and "open sharing of ideas" was rated as 4.04 on average. Mean ratings regarding whether the "authority structure was clearly defined and followed" was 4.18. Respondents $(\mathrm{n}=9)$ who "strongly agreed" with the statement that they were satisfied with the partnership also gave slightly higher mean scores to all the remaining statements in the table, including items related to good communication (4.88), open sharing of ideas (4.78), university autonomy (4.67), and clearly defined authority structure (4.78).

Table 1. Ratings of perceptions of collaboration $(\mathrm{N}=24)$.

\begin{tabular}{cccccccc}
\hline Level of agreement & Mean & SA(5) & $\boldsymbol{A ( 4 )}$ & $\boldsymbol{N}(3)$ & $\boldsymbol{D}(2)$ & $\boldsymbol{S D}(\mathbf{1})$ & Missing \\
\hline Satisfied with the partnership & 4.14 & $38 \%$ & $38 \%$ & $8 \%$ & $8 \%$ & $0 \%$ & $8 \%$ \\
Satisfied with level of state involvement & 4.09 & $29 \%$ & $50 \%$ & $8 \%$ & $0 \%$ & $4 \%$ & $8 \%$ \\
University able to meet contractual expect & 4.40 & $58 \%$ & $25 \%$ & $0 \%$ & $4 \%$ & $4 \%$ & $8 \%$ \\
State able to meet contractual expectations & 4.31 & $42 \%$ & $46 \%$ & $0 \%$ & $0 \%$ & $4 \%$ & $8 \%$ \\
Good state and university communication & 4.18 & $33 \%$ & $46 \%$ & $8 \%$ & $4 \%$ & $0 \%$ & $8 \%$ \\
Open sharing of ideas between state/university & 4.04 & $29 \%$ & $42 \%$ & $13 \%$ & $0 \%$ & $4 \%$ & $13 \%$ \\
University partner has organizational autonomy & 3.95 & $29 \%$ & $38 \%$ & $17 \%$ & $8 \%$ & $0 \%$ & $8 \%$ \\
Authority structure clearly defined/followed & 4.18 & $38 \%$ & $33 \%$ & $21 \%$ & $0 \%$ & $0 \%$ & $8 \%$ \\
\hline
\end{tabular}

\subsubsection{Perceptions of Challenges}

Respondents were asked to rate on a scale from strongly agree (5) to strongly disagree (1) nine statements pertaining to challenges in partnerships. Means are reported here and percentages for each answer category appear in Table 2. The highest rated challenge pertained to the "integration of multiple financial systems" at 3.54, while the lowest rated challenge (2.81) was for "consistent inter-organizational communication". Other challenge ratings included 3.31 for "conflicting organizational cultures"; 3.28 for avoiding a "super-bureaucracy" and 3.22 for "integration of multiple technology systems". "Implementing evidence-based practice" was rated as 3.04 on average; "meeting matching dollar requirements" and the "dissemination of evaluative research" were rated at 2.95 on average. Furthermore, "meeting state human resource needs" received a rating of 2.86 .

Table 2. Respondents rating that challenge is present in partnership $(\mathrm{N}=24)$.

\begin{tabular}{lccccccc}
\hline \multicolumn{1}{c}{ Level of agreement } & Mean & SA(5) & A(4) & N(3) & D(2) & SD(1) & Missing \\
\hline Integration of multiple financial systems & 3.54 & $29 \%$ & $29 \%$ & $8 \%$ & $13 \%$ & $13 \%$ & $8 \%$ \\
Integration of multiple technology systems & 3.22 & $17 \%$ & $21 \%$ & $25 \%$ & $25 \%$ & $4 \%$ & $8 \%$ \\
Dissemination of evaluation research & 2.95 & $4 \%$ & $29 \%$ & $29 \%$ & $17 \%$ & $13 \%$ & $8 \%$ \\
Implementing evidence based practices & 3.04 & $4 \%$ & $33 \%$ & $25 \%$ & $21 \%$ & $8 \%$ & $8 \%$ \\
Avoiding "super-bureaucracy" & 3.28 & $13 \%$ & $29 \%$ & $29 \%$ & $4 \%$ & $13 \%$ & $13 \%$ \\
Meeting state human resource needs & 2.86 & $21 \%$ & $17 \%$ & $4 \%$ & $29 \%$ & $21 \%$ & $8 \%$ \\
Meeting matching dollar requirements & 2.95 & $13 \%$ & $29 \%$ & $8 \%$ & $25 \%$ & $17 \%$ & $8 \%$ \\
Conflicting organizational cultures & 3.31 & $13 \%$ & $33 \%$ & $21 \%$ & $21 \%$ & $4 \%$ & $8 \%$ \\
Consistent inter-organizational & 2.81 & $0 \%$ & $29 \%$ & $29 \%$ & $21 \%$ & $13 \%$ & $8 \%$ \\
communication & & & & & & & \\
\hline
\end{tabular}




\subsection{Comparisons of Partnership Characteristics and Matching Dollar Requirement}

Given the importance of matching dollar contributions from universities to these child welfare training partnerships, chi-square analyses were conducted with key program variables (Table 3) to assess differences in program characteristics and matching dollar requirements. These results suggested statistically significant differences in years the contract was maintained and matching dollar expectations. Almost $90 \%$ of partnership that had maintained a contract for over 10 years had a match requirement, as compared to $40 \%$ of those with a contract for 10 years or less $\left(X^{2}=5.11\right.$, df $=1$, $p=0.024, \mathrm{n}=24)$. There were no other statistically significant differences in match expectation and program characteristics.

Table 3. Characteristics of Child Welfare Partnerships and Prevalence (\%) of Matching Dollar Requirements $(\mathrm{N}=24)$.

\begin{tabular}{|c|c|c|c|}
\hline Characteristic & All & Match requirement & No Match requirement \\
\hline \multicolumn{4}{|l|}{ Primary service provided } \\
\hline Child welfare training program & 62 & 67 & 33 \\
\hline IV-E Tuition/Stipend & 23 & 71 & 29 \\
\hline Other & 12 & 100 & 0 \\
\hline Missing & 0 & & \\
\hline \multicolumn{4}{|l|}{ Years contract maintained* } \\
\hline 10 or less & 21 & 40 & 60 \\
\hline More than 10 & 79 & 88 & 12 \\
\hline Missing & 0 & & \\
\hline \multicolumn{4}{|l|}{ Number students } \\
\hline 20,000 and less & 46 & 60 & 40 \\
\hline More than 20,000 & 50 & 92 & 8 \\
\hline Missing & 4 & & \\
\hline \multicolumn{4}{|l|}{ Must have match } \\
\hline Yes & 65.4 & & \\
\hline No & 19.2 & -- & -- \\
\hline Missing & 15.4 & -- & -- \\
\hline
\end{tabular}

\subsection{Comparisons of Perceptions of Collaboration and Matching Dollar Requirement}

To assess differences in collaboration items and matching dollar requirements, chi-square analyses were conducted using dichotomized ("any agreement" versus "other") responses to collaboration items (Table 4). These results suggested statistically significant differences in satisfaction with the partnership and matching dollar expectations. Just under $30 \%$ of partnerships that had a matching dollar requirement were satisfied with the partnership as compared to $80 \%$ of those with no match expectation $\left(\mathrm{X}^{2}=4.09\right.$, $\left.\mathrm{df}=1, p=0.05, \mathrm{n}=22\right)$. There were no other statistically significant differences in match expectation and collaboration items. 
Table 4. Prevalence (\%) of agencies reporting strong agreement to collaboration items by matching dollar requirement $(N=22)$.

\begin{tabular}{cccc}
\hline Strongly agree regarding collaboration & $\begin{array}{c}\text { University resource match } \\
(\mathbf{n}=\mathbf{1 7})\end{array}$ & $\begin{array}{c}\text { No match } \\
(\mathbf{n}=\mathbf{5})\end{array}$ & $\mathbf{X}^{\mathbf{2}} \mathbf{( 1 )}$ \\
\hline Satisfied with the partnership* & $29(5)$ & $80(4)$ & 4.090 \\
Satisfied with level of involvement from state & $24(4)$ & $60(3)$ & 2.369 \\
University able to meet contractual expect & $53(9)$ & $100(5)$ & 3.679 \\
State able to meet contractual expectations & $30(5)$ & $60(3)$ & 1.562 \\
Good state and university communication & $30(5)$ & $60(3)$ & 1.562 \\
Open sharing of ideas between state/university & $25(4)$ & $60(3)$ & 2.100 \\
University partner has organizational autonomy & $24(4)$ & $60(3)$ & 2.369 \\
Authority structure clearly defined/followed & $35(6)$ & $60(3)$ & 0.976 \\
\hline
\end{tabular}

${ }^{*} p \leq 0.05 ; * * \leq 0.01 ; * * * p \leq 0.001$.

\subsection{Comparisons of Perceptions of Challenge and Matching Dollar Requirement}

Furthermore, given the importance of university matching dollar contributions, chi-square analyses were conducted using dichotomized challenges responses (Table 5) to assess differences in perceptions of challenge and matching dollar requirements. These results suggested statistically significant differences in two measures of challenge within partnerships and matching dollar expectations. There were statistically significant differences in whether respondents reported that implementing evidence based practices was a challenge, with $100 \%$ of those with a matching dollar requirement reporting such a challenge and $60 \%$ of those with no matching requirement reporting this challenge $\left(\mathrm{X}^{2}=7.480\right.$, $\mathrm{df}=1, p=0.006, \mathrm{n}=22$ ) There were also statistically significant differences in whether respondents reported that "avoiding a "super-bureaucracy" was a challenge, with $100 \%$ of those with a matching dollar requirement reporting such a challenge and $40 \%$ of those with no matching requirement reporting this a challenge $\left(\mathrm{X}^{2}=11.20, \mathrm{df}=1, p=0.001, \mathrm{n}=22\right)$. There were no other statistically significant differences in match expectation and challenge items.

Table 5. Prevalence (\%) of agencies reporting some amount of challenge (strongly agree or agree) in partnership by requirement to match with university resources $(N=22)$.

\begin{tabular}{cccc}
\hline Some amount of challenge present & $\begin{array}{c}\text { University resource match } \\
(\mathbf{n}=\mathbf{1 7})\end{array}$ & $\begin{array}{c}\text { No match } \\
(\mathbf{n}=\mathbf{5})\end{array}$ & $\mathbf{X}^{2} \mathbf{r}$ (1) \\
\hline Integration of multiple financial systems $^{\text {a }}$ & $94(16)$ & $60(3)$ & 3.819 \\
Integration of multiple technology systems $^{\text {a }}$ & $100(17)$ & $80(4)$ & 3.562 \\
Dissemination of evaluation research $^{\text {c }}$ & $94(16)$ & $60(3)$ & 3.819 \\
Implementing evidence based practices ** $_{\text {Avoiding "super-bureaucracy" *** }}$ & $100(17)$ & $60(3)$ & 7.480 \\
Meeting state human resource needs & $100(17)$ & $40(2)$ & 11.200 \\
Conflicting organizational cultures & $82(14)$ & $60(3)$ & 1.099 \\
Consistent inter-organizational communication & $100(17)$ & $80(4)$ & 3.562 \\
\hline
\end{tabular}

$$
{ }^{\mathrm{a}} p=0.051,{ }^{*} p \leq 0.05,{ }^{* *} p \leq 0.01,{ }^{* * *} p \leq 0.001 .
$$




\subsection{Comparisons of Perceptions of Collaboration and Years of Contract}

The authors wanted to examine whether or not there were differences in how well universities and state child welfare agencies collaborated in these partnerships, given the number of years they had maintained their contractual relationship. To assess differences in collaboration items and "years with a contract," chi-square analyses were conducted using dichotomized ("any agreement" versus "other") responses to collaboration items (Table 6). These results suggested statistically significant differences in three of the collaboration items and years with a contract. First, there were statistically significant associations between "satisfaction with the partnership" and "years with a contract," with $80 \%$ of those partnerships with a contract for 10 years or less reporting satisfaction, as compared to $29 \%$ of those with a contract for more than 10 years $\left(\mathrm{X}^{2}=4.09\right.$, $\left.\mathrm{df}=1, p=0.043, \mathrm{n}=22\right)$. Second, there were statistically significant associations between perceptions of "university partners autonomy" and "years with a contract," with $80 \%$ of those partnerships with a contract for 10 years or less reporting autonomy of university partner, as compared to $18 \%$ of those with a contract for more than 10 years $\left(\mathrm{X}^{2}=6.92, \mathrm{df}=1, p=0.009, \mathrm{n}=22\right)$. Third, there were statistically significant associations between perceptions of whether "the authority structure was clearly defined" and "years with a contract," with $80 \%$ of those partnerships with a contract for 10 years or less maintaining this view, as compared to $29 \%$ of those with a contract for more than 10 years $\left(\mathrm{X}^{2}=4.09, \mathrm{df}=1, p=0.043, \mathrm{n}=22\right)$. There were no other statistically significant differences in match expectation and collaboration items.

Table 6. Prevalence (\%) of agencies reporting strong agreement to collaboration items by years with contract $(N=22)$.

\begin{tabular}{|c|c|c|c|}
\hline Strongly agree regarding collaboration & $\begin{array}{c}10 \text { years or less } \\
\text { with contract } \\
(n=5)\end{array}$ & $\begin{array}{l}\text { More than } 10 \text { years } \\
\text { with contract } \\
(\mathbf{n}=17)\end{array}$ & $\begin{array}{l}X^{2} \\
(1)\end{array}$ \\
\hline Satisfied with partnership* & $80(4)$ & $29(5)$ & 4.090 \\
\hline Satisfied with level of involvement from state & $60(3)$ & $24(4)$ & 2.369 \\
\hline University able to meet contractual obligations & $80(4)$ & $59(10)$ & .749 \\
\hline State able to meet contractual obligations & $60(3)$ & $30(5)$ & 1.562 \\
\hline Good state and university communication & $60(3)$ & $30(5)$ & 1.562 \\
\hline Open sharing of ideas between state/university & $60(3)$ & $25(4)$ & 2.100 \\
\hline University partner has autonomy** & $80(4)$ & $18(3)$ & 6.924 \\
\hline Authority structure clearly defined/followed* & $80(4)$ & $30(5)$ & 4.090 \\
\hline
\end{tabular}

\subsection{Comparisons of Perceptions of Challenge and Years of Contract}

Similarly, the authors also wanted to explore whether or not there was a significant difference in the challenges experienced by administrators in more long-term contractual partnerships as compared to those in relatively newer contractual relationships. Therefore, chi-square analyses were conducted using dichotomized challenge responses (Table 7) to assess differences in perceptions of challenge and "years with a contract". These results suggested statistically significant differences in three measures of challenge within partnerships and years with a contract. There were statistically significant differences in whether respondents reported that disseminating evaluation research was a challenge, 
with $40 \%$ of those with a contract of 10 years or less reporting such a challenge and $100 \%$ of those with contracts for more than 10 years reporting this challenge $\left(\mathrm{X}^{2}=11.811, \mathrm{df}=1, p=0.001, \mathrm{n}=22\right)$. There were statistically significant differences in whether respondents reported that implementing evidence based practices was a challenge, with $60 \%$ of those with a contract for 10 years or less reporting such a challenge and $100 \%$ of those with a contract for more than 10 years reporting this challenge $\left(\mathrm{X}^{2}=7.480, \mathrm{df}=1, p=0.006, \mathrm{n}=22\right)$. There were statistically significant differences in whether respondents reported that "meeting state human resource needs" was a challenge, with $40 \%$ of those with a contract for 10 years or less reporting such a challenge and $88 \%$ of those with a contract for more than 10 years reporting this challenge $\left(\mathrm{X}^{2}=5.119, \mathrm{df}=1, p=0.024, \mathrm{n}=22\right)$. Finally, there were statistically significant differences in whether respondents reported that "meeting matching dollar requirements" was a challenge, with $20 \%$ of those with a contract for 10 years or less reporting such a challenge and $100 \%$ of those with a contract for more than 10 years reporting this challenge $\left(\mathrm{X}^{2}=16.622, \mathrm{df}=1, p=0.000, \mathrm{n}=22\right)$. There were no other statistically significant differences in years with a contract and challenge items.

Table 7. Prevalence (\%) of agencies reporting some amount of challenge (strongly agree or agree) in partnership by years with contract $(N=22)$.

\begin{tabular}{|c|c|c|c|}
\hline Some level of challenge in partnership & $\begin{array}{c}10 \text { years or less } \\
\text { with contract } \\
(n=5)\end{array}$ & $\begin{array}{c}\text { More than } 10 \text { years } \\
\text { with contract } \\
(\mathbf{n}=17) \\
\end{array}$ & $\begin{array}{l}X^{2} \\
(1)\end{array}$ \\
\hline Integration of multiple financial systems $\mathrm{s}^{\mathrm{a}}$ & $60(3)$ & $94(16)$ & 3.819 \\
\hline Integration of multiple technology systems & $80(4)$ & $100(17)$ & 3.562 \\
\hline Dissemination of evaluation research $* * *$ & $40(2)$ & $100(17)$ & 11.811 \\
\hline Implementing evidence based practices $* *$ & $60(3)$ & $100(17)$ & 7.480 \\
\hline Avoiding "super-bureaucracy" & $60(3)$ & $94(16)$ & 3.544 \\
\hline Meeting state human resource needs * & $40(2)$ & $88(15)$ & 5.119 \\
\hline Meeting matching dollar requirements $* * *$ & $20(1)$ & $100(17)$ & 16.622 \\
\hline Conflicting organizational cultures & $80(4)$ & $100(17)$ & 3.562 \\
\hline Consistent inter-organizational communication ${ }^{a}$ & $60(3)$ & $94(16)$ & 3.819 \\
\hline
\end{tabular}

$$
{ }^{\mathrm{a}} p=0.051, * p \leq 0.05,{ }^{* *} \mathrm{p} \leq 0.01, * * * p \leq 0.001 .
$$

\section{Discussion}

The findings of this study indicate that university-state child welfare training partnerships with contractual relationships of over 10 years were more likely to require the university to match state contract dollars with some percentage of a dollar contribution from the university. Almost $90 \%$ of the long-term partnerships in the survey had a university matching dollar requirement in the contract, as compared to $40 \%$ of those with a contract of 10 years or less. At the same time, those university survey respondents with matching dollar requirements in their contracts appeared less satisfied with the partnership. That is, $30 \%$ of the university respondents with match requirements indicated they were satisfied with the partnership as compared to $80 \%$ of those with no match expectation. Those with a matching dollar requirement were also more likely to experience challenges with avoiding a "super-bureaucracy." 
Contracts governing university-state child welfare training partnerships often require university partners to make a dollar contribution, because state child welfare agencies gain added benefit from the relationship - including increased federal funding. Yet, not all state agencies involved in training partnerships with universities require a substantial university matching contribution. Variations in what states require from universities depend on several factors such as the unique political climate of the state, the amount of child welfare staff training money available to the state, the unique mission and priorities of university partners, and individual university policies on the administration of indirect costs involving facilities and administration. States with more conservative approaches to the use of state government in promoting child welfare may limit discretionary funds available for staff training. Similarly, relatively poor states may limit such funding. The specific items on which individual states are allowed to spend their Title IV-E funds may be interpreted somewhat differently by administrators in various regions of the nation.

Furthermore, the amount of university resources available for child welfare training partnerships with the state is contingent on the university mission as well as the values and policies of top university administrators regarding community service and engagement. Some colleges and universities emphasize community engagement in their mission and strategic plans more than others; state land grant universities have a unique obligation to such service. In addition, one way that universities generate matching dollar contributions in their state training contracts is through contributions of costs associated with university facilities and administration. However, these costs are based, in part, on rates negotiated between the federal government and individual universities. As a result, these indirect cost rates vary among universities and over time at a given university.

\section{Implications for Administrative Practice}

University and state child welfare training partnerships have the potential to be mutually beneficial relationships for both systems. State child welfare agencies require ongoing inputs of highly trained staff, the latest technologies, and current evidence-based literature. Universities may benefit from increased opportunities for student field placements, service learning, and job placement as well as for faculty research, presentations, and service. University survey participants who "strongly agreed" with the statement that they were satisfied with the partnership (see Table 1) also gave higher mean responses than other survey participants to all the remaining collaboration items in Table 1, including the items dealing with communication and boundaries between the two systems (good communication, open sharing of ideas, university autonomy, and clearly defined authority structure).

Yet, the findings of this survey indicate public university administrators face certain challenges in collaborating with state child welfare agencies. University-child welfare agency training partnerships represent a collaboration of two large bureaucracies with their respective internal cultures, policies, technologies, and financial systems. Because of this, the active involvement and support of top university administrators (i.e., deans and department chairs) must be emphasized. The financial impact on the social work education program of potential shortfalls in university matching dollar obligations must be proactively discussed. Social work faculty members must be informed of, agree to, and follow through on their individual obligations in the contract. Such cooperation requires time and vigilance on the part of university administrators of the partnership. These findings on grants management are 
consistent with the conclusions of Jhirad-Reich in 2002; the difference now is that recent cuts in higher education may result in less time for such administrative attention by universities $[1,20]$.

This study found that partnerships with contracts involving matching dollar contributions from universities are more likely to face challenges with avoiding a "super-bureaucracy". This finding may be explained by the added coordination and documentation that such dollar matches require from each partner. Those entering such partnerships must find ways to streamline required reporting and paperwork while speaking a common financial language across bureaucratic systems. This typically requires close coordination by both the social work education program and the state child welfare agency with the university contracts (i.e., sponsored programs) office. In times of university and state government staff reductions, the added time and effort entailed can produce stress on both sides of the partnership.

Furthermore, if these training relationships are to be mutually satisfactory and sustainable, faculty and students must see concrete benefits to participation in university-state child welfare training partnerships also. To achieve promotion and tenure, faculty members need to disseminate their research. Students in field placements with state agencies expect to apply the latest in evidence-based methodologies. Yet, survey respondents in more long-term training partnerships were more likely to face challenges in disseminating evaluation research and facilitating the implementation of evidencebased child welfare practices. This finding runs counter to Zlotnik's call for greater evaluation, while providing current data to support the 2007 findings of Chavkin and Lee [7,21]. A possible explanation is that early contracts governing training partnerships may not have been as sophisticated in terms of research and evaluation. In contrast, a current emphasis on "continuous quality improvement" and "best practice" in child welfare staff development and training requires better dissemination of program evaluation results and the implementation of evidence-based knowledge. University administrators may be wise to stress this point during contract negotiations and renewals, when university priorities and the "value added" by university partners are delineated.

In any case, future success with these challenges will require a greater knowledge and sensitivity on the part of university administrators and researchers regarding the politics of evaluation as well as organizational change in public child welfare systems. To this end, a limitation of this survey is that it examines just the university perspective on administering university-state child welfare training partnerships [6]. This represents one stakeholder's perspective. Future research should attempt to also gain a better understanding of the views of state child welfare administrators regarding the issues identified in this survey in an effort to promote better intersystem communication and collaboration, while sustaining such partnerships over the long-term.

\section{Acknowledgements}

This research was originally presented in draft form at the Council of Social Work Education (CSWE) in November 2012 (Washington D.C.). The authors would like to acknowledge the assistance of MSW students Sarah Gross and Nina Foucheaux.

\section{Conflicts of Interest}

The authors declare no conflict of interest. 


\section{References}

1. Mosle, S. Does Class Size Count? The New York Times, 5 May 2013, SR4.

2. Children's Defense Fund. About child welfare. Available online: http://www.childrensdefense.org/ policy-priorities/child-welfare/about.html (accessed on 4 April 2013).

3. U.S. Department of Health and Human Services, Administration for Children and Families, Administration on Children, Youth and Families, Children's Bureau. Child Maltreatment 2011. Available online: http://www.acf.hhs.gov/sites/default/files/cb/cm11.pdf (accessed on 4 April 2013).

4. Federal Interagency Forum on Child and Family Statistics. America's Children: Key National Indicators of Well-Being, 2013. Available online: http:/www.childstats.gov/americaschildren/ demo.asp (accessed on 4 April 2013).

5. Vining, A.R.; Boardman, A. Public-private partnerships in Canada: Theory and evidence. Can. Publ. Admin. 2008, 51, 9-44.

6. Stuart, J.B.; Walker, J.T.; Minzner, A. A Critical Review of Partnership Capacity and Effectiveness: Moving from Theory to Evidence; Abt Associates: Bethesda, MD, USA, 2011.

7. Chavkin, N.; Lee, A. A national survey of title IV-E evaluations: Professional development. Int. J. Cont. Soc. Work Educ. 2007, 10, 36-46.

8. University of Vermont. Vermont Child Welfare Training Partnership. Available online: http://www.uvm.edu/ socwork/vcwp/?Page=about.html\&SM=aboutsubmenu.html (accessed on 14 October 2013).

9. American Public Human Services Association. Pitt child welfare training program wins national award. Available online: http://aphsa.org/Home/Doc/UofPittsburgh.pdf (accessed on 5 October 2013).

10. Zlotnik, J.L.; Strand, V.C.; Anderson, G.R. Achieving positive outcomes for children and families: Recruiting and retaining a competent child welfare workforce. Child Welfare 2009, 88, 7-21.

11. Lieberman, A.; Hornby, H.; Russell, M. Analyzing the educational backgrounds and work experiences of child welfare personnel: A national study. Soc. Work 1988, 33, 485-489.

12. Scannapieco, M.; Connell-Corrick, K. Do collaborations with schools of social work make a difference for the field of child welfare? J. Hum. Behav. Soc. Environ. 2003, 7, 35-51.

13. Hopkins, K.M.; Mudrick, N.R.; Rudolph, C.S. Impact of university/agency partnerships in child welfare on organizations, workers \& work activities. Child Welfare 1999, 78, 749-773.

14. Child Welfare League of America (CWLA). Workforce Recruitment and Retention in Child Welfare: A Review of the Literature; Child Welfare League of America: Washington, DC, USA, 2005; pp.1-9.

15. U.S. General Accounting Office. Child Welfare: HHS Could Play a Greater Role in Helping Child Welfare Agencies Recruit and Retain Staff; GAO-03-357; General Accounting Office: Washington, DC, USA, 2003.

16. Faller, K.C.; Grabarek, M.; Ortega, R.M. Commitment to child welfare work: What predicts leaving and staying? Child Youth Serv. Rev. 2010, 32, 840-846.

17. Social Work Policy Institute. Professional Social Workers in Child Welfare Work: Research Addressing the Recruitment and Retention Dilemma. Available online: http://www.socialworkpolicy.org/research/child-welfare-2.html (accessed on 12 August 2013). 
18. Robin, S.C.; Hollister, C.D. Career paths and contributions of four cohorts of IV-E funded MSW child welfare graduates. J. Health Soc. Pol. 2002, 15, 53-67.

19. Institute for the Advancement of Social Work Research. Strengthening university/agency research partnerships to enhance child welfare outcomes: A toolkit for building research partnerships. Available online: http://www.ppcwg.org/images/files/Toolkit\%20for\%20Building\%20Research\% 20Partnerships.pdf (accessed on 12 August 2013).

20. Jhirad-Reich, J. Operational Issues in Child Welfare Grants Management; Council on Social Work Education: Alexandria, VA, USA, 2002.

21. Zlotnik, J.L. Enhancing child welfare service delivery: Promoting agency-social work education partnerships. Pol. Pract. Publ. Hum. Serv. 2001, 59, 24-27.

(C) 2013 by the authors; licensee MDPI, Basel, Switzerland. This article is an open-access article distributed under the terms and conditions of the Creative Commons Attribution license (http://creativecommons.org/licenses/by/3.0/). 